\title{
Bacterial challenges and evolving antibacterial drug strategy
}

\section{B. Watt and J.G. Collee}

Bacteriology Laboratory, City Hospital, Edinburgh EH10 5SB and Department of Medical Microbiology, University Medical School, Edinburgh EH8 9AG, UK

\section{Introduction}

In this paper, we attempt to summarize developments of importance for practising hospital clinicians and for primary care doctors who must be aware of the ever-widening spectrum of recognized pathogens. This article is restricted to considerations of pathogenic bacteria and antibacterial drugs that have obliged us to change our strategies or policies in the last decade or so. There have been many confusing developments. Whilst basically new antibacterial drugs are rare, variations on previously successful models have been very numerous and some significant progress has been made.

Over the decade, several new infective challenges have posed problems for clinicians and microbiologists. It is recognized that communityacquired infections differ from hospital-acquired infections in the range and nature and antibiotic resistance profiles of the causative organisms. The inexorable progress of bacterial drug resistance has obliged us to reconsider first-choice therapy for some infections.

Beta-lactamase production by various bacteria has restricted our therapeutic options or has obliged us to use new preparations. For example, our recognition of the pathogenic potential of Moraxella (Branhamella) catarrhalis has required modification of previous approaches to the antibiotic therapy of respiratory tract infections, and beta-lactamase-producing strains of Haemophilus influenzae have created further problems. Worrying outbreaks of a range of infections from legionellosis to salmonellosis have extended us to determine or define appropriate therapy. Our evolving awareness of human immunodeficiency virus (HIV) disease and associated opportunistic

Correspondence: B. Watt. M.D., F.R.C.Path. bacterial infections obliges us to consider a variety of new challenges, especially mycobacterial infections.

Our relative lack of success in dealing with some aggressive infections, such as those caused by the meningococcus or Haemophilus influenzae, has called for a review of our prophylactic strategies, and this has been highlighted in the case of pneumococcal challenges in compromised (asplenic) patients. The common occurrence of polymicrobial or mixed bacterial infections has been acknowledged, and the neglected concept of pathogenic synergy has been revived. The problemsô of antibiotic-associated diarrhoea have necessitated? scrutiny of precipitating antibiotics and studies of the most effective therapy. Meanwhile, the general acceptance of the principle of peroperative antimicrobial prophylaxis and its application to specific areas of operative surgery has had a major impact.

\section{Changes in first-line choices}

The sulphonamides have been largely superseded by newer drugs in the last decade, though they are still used, often in conjunction with trimethoprim (as cotrimoxazole), in the treatment of uncomplicated urinary tract infections. Resistance to sulphonamides is common and it is arguable that the use of the combination is now often irrational. Thus, trimethoprim has emerged as a single drug in its own right, but its use too has often been overtaken by the development of resistance. Nalidixic acid has been superseded by the development of the more potent 4-quinolones, and nitrofurantoin is not favoured by many clinicians. Some of these drugs have special roles that maintain them in our formularies for the 1990s although they are not now in general daily use.

The lincosamides, notably clindamycin, had special virtues that endeared them to orthopaedic 
surgeons and others who valued their efficacy against gram-positive cocci and anaerobes and their good penetration into bone. Clindamycin is still highly regarded as an alternative to penicillin when such an option is sought. Unfortunately, the association with pseudomembranous colitis (PMC) has understandably inhibited the general use of clindamycin. It should be noted that the volume of use of ampicillin ensures that ampicillin features prominently in the PMC league table; our experience in the last decade shows that no antibiotic is exempt. Nevertheless, the association with the lincosamides is especially clear and is a justifiable (though not absolute) restraint.

The staphylococcus has sequentially challenged all of the antibacterial drugs as they have been developed and widely used, and has obliged us to keep our therapeutic options open. Thus, fusidic acid (usually in combination with another drug) is still useful. Strains of methicillin resistant Staphylococcus aureus (MRSA) have posed special problems. Vancomycin retains a remarkable place in our attempts to control coagulase-negative staphylococcal infections and MRSA infections (and pseudomembranous colitis caused by Clostridium difficile). It is worrying that our options in these difficult situations are so limited and that we are so dependent on such a restricted number of active agents.

\section{The basic armament}

Many antibacterial drugs have stood the test of time, despite our abuse of them over the years. Accordingly, the list of those regarded as first-line choices for the 1990s does not differ significantly from the 1980 list. We now consider developments in antibacterial drug strategy and practice in the last decade in relation to changing aspects of infection. The following account reviews developments in the use of our main-line antibacterial drugs and draws attention to important new applications.

\section{The penicillins}

Williams ${ }^{1}$ recognized the following 4 groups of penicillins.

Group I contains benzyl penicillin (penicillin G), the original and still probably the best, ${ }^{2}$ and analogues such as the orally active phenoxymethyl penicillin (penicillin V).

Group II contains the anti-staphylococcal methicillin and the clinically useful orally active cloxacillin series.

Group III contains penicillins with activity against Gram-negative bacilli (coliform organisms and Haemophilus species etc.), but susceptible to beta-lactamases. These include: (1) ampicillin and amoxycillin (the amino penicillins); (2) carbenicillin and other carboxypenicillin analogues; (3) acyl ureido penicillins such as mezlocillin, azlocillin and piperacillin; and (4) amidino penicillins such as mecillinan. It is most important to note in practice that none of the Group III penicillins is completely stable to the beta-lactamases.

Group IV holds the only true penicillin that is beta-lactamase stable, temocillin, but the activity of this drug does not extend beyond the aerobic Gram-negative bacteria.

Beta-lactamase inhibitors As bacterial resistance to beta-lactam antibiotics is largely attributable to potent bacterial beta-lactamases, pharmaceutical companies sought to develop beta-lactam drugs that are resistant to these enzymes (q.v.). Another strategy is to develop preparations in which a sensitive beta-lactam drug is protected by a betalactamase inhibitor such as clavulanic acid or sulbactam or tazobactam.

These inhibitors have some antibacterial activity in their own right, but their role in the combination is to shield the more active drug. This has extended the usefulness of drugs such as amoxycillin against beta-lactamase-producing staphylococci, coliform organisms and anaerobes including Bacteroides fragilis. However, Pseudomonas aeruginosa has innate resistance to amoxycillin and this still holds.

The combination of amoxycillin with clavulanic acid (co-amoxiclav) is marketed in Britain as Augmentin; ticarcillin with clavulanic acid is Timentin; and ampicillin with sulbactam is sultamicillin. $^{3}$ Tazobactam in combination with piperacillin is a useful development of this theme. ${ }^{4}$ Meanwhile, the pharmaceutical industry was developing the cephalosporins as an alternative answer to the threat of the penicillinases.

\section{The cephalosporins and related drugs}

These drugs can be classified into 4 groups that reflect an extending clinical requirement for a range of activity or specific efficacy. ${ }^{s}$

Group I drugs (examples cephaloridine, cephazolin) are highly active against Gram-negative bacteria, notably staphylococci and streptococci.

Group II cephalosporins (examples cefamandole, cefuroxime) are effective against Gram-positive cocci and (Gram-negative) coliform organisms, but not pseudomonas.

Group III drugs (examples cefotaxime, ceftazidime) are active against Pseudomonas and related species, in addition to their activity against enterobacteria. Cefotaxime is less active than ceftazidime against Pseudomonas aeruginosa. Cefsulodin was developed specifically as an antipseudomonal cephalosporin. 
Group IV contains the cephamycins (examples cefoxitin, latamoxef, cefotetan) with broadspectrum efficacy that includes activity against anaerobic bacilli such as bacteroides organisms, the clostridia, and anaerobic cocci.

As in the case of the penicillins, it should be noted that evolving bacterial resistance may limit the usefulness of the drugs in each of these groups.

\section{Monobactams}

Aztreonam is a monocyclic beta-lactam with remarkably narrow-spectrum activity against aerobic Gram-negative bacteria, notably the enterobacteria, the gonococcus and Haemophilus influenzae. $^{6}$

\section{Carbapenems}

Imipenem has a remarkably broad spectrum of activity against the enterobacteria, and Pseudomonas aeruginosa, Haemophilus influenzae, Bacteroides spp., staphylococci and streptococci. ${ }^{7}$ Imipenem has to be given with cilastatin to inhibit the action of renal dehydropeptidase which inactivates the drug. Meropenem has equivalent activity and is resistant to the action of the renal enzyme. ${ }^{8}$

For comparative data on the beta-lactam antibiotics, the reader is referred to Rolinson's informed paper. ${ }^{9}$ An account of the mechanisms and clinical significance of resistance to new betalactam antibiotics is given by Livermore and Wood. ${ }^{10}$

\section{Aminoglycosides}

These drugs are not absorbed after ingestion and are normally injected, unless a local effect on an intestinal pathogen or on the gut flora is desired. In the latter case, aminoglycosides are still used irrationally because they are not effective against anaerobic bacteria or streptococci, though they have a synergistic effect with penicillin when used in combination parenterally against streptococci.

Streptomycin now has only a limited place in the management of tuberculous infections, and it has been largely replaced in the therapy of other serious infections by more recent members of the series such as gentamicin, tobramycin, netilmicin, and amikacin. ${ }^{11}$ With the exception of amikacin, these later developments are not adequately effective against the tubercle bacillus. They all have prompt and highly useful activity against coliform bacteria including pseudomonas, though resistance is a recurring problem if they are not used carefully. It should be remembered that therapy with aminoglycosides may suppress the growth of mycobacteria in specimens submitted for culture to exclude a diagnosis of tuberculosis. This is import- ant in the laboratory investigation of a patient with an undiagnosed infection that might be mycobacterial, especially at the present time when opportunistic mycobacterial infections in compromised patients test our vigilance.

Mattie et al..$^{12}$ argued that the relative efficacy of different aminoglycosides should be properly quantitated and should be related to relative toxicity.

Aminoglycosides have been widely used for many years. Although resistance is a problem in specific areas, a recent survey in the UK ${ }^{13}$ showed that overall resistance rates amongst normally sensitive bacterial genera ranged from $2.4 \%$ for amikacin to $3.7 \%$ for gentamicin. For individual genera, e.g. Serratia spp., resistance rates were higher. In general, the lowest resistance rates were seen for amikacin. An earlier European survey ${ }^{14}$ had revealed gentamicin resistance rates as high as $30 \%$ in some countries. There is no doubt that increased usage of a given aminoglycoside can lead to increased resistance to that aminoglycoside, but also to decreased resistance rates to other aminoglycosides. A recent study ${ }^{15}$ showed that when amikacin was the main aminoglycoside used in cancer treatment centres in the USA, there was an increase in resistance to amikacin but a decrease in resistance to gentamicin and tobramycin.

Although the toxicity of the aminoglycosides for the middle ear and the kidney limits their use ando obliges the clinician to monitor peak and trough levels during therapy, these drugs are still favoured by many clinicians for the therapy of serious infections. They are often used in combination with a pencillin and sometimes with metronidazole to extend the spectrum until the nature of the infection is known. This is an area of current debate, as others prefer to base therapy in such circumstances on one of the broad-spectrum cephalosporins or related drugs such as ceftazidime and to add in other drugs as necessary. ${ }^{16}$

Spectinomycin has special usefulness in the treatment of gonococcal infections (1) in patients who are allergic to penicillin, or (2) in cases of infection with penicillinase-producing strains. ${ }^{17}$

\section{Tetracyclines}

These drugs were active across a remarkably wide spectrum, but bacterial resistance and recognized adverse effects limit their use. ${ }^{18}$

The adverse effects of the tetracyclines are mainly related to the gastro-intestinal tract and superinfection, and to the sequestering of the drug in bone and teeth so that they are not given as a routine during pregnancy or childhood. It was later found that the anti-anabolic effect of tetracyclines may precipitate or exacerbate renal failure in patients with impaired renal function. 
Chlortetracycline, oxytetracycline and tetracycline are very similar in their action. Demethylchlortetracycline was introduced in 1957 as a long-acting variant. Doxycycline and minocycline were introduced more recently; they do not exacerbate renal failure and, as they also have the advantage of longer half-lives and marginally better activity, they are the currently preferred preparations. Dizziness and vertigo are listed among the adverse side effects of minocycline. Porphyria is a contraindication to the use of doxycycline.

The tetracyclines retain rather a mixed range of applications, having been displaced from so many first-line positions. ${ }^{19}$ They have a major role in the treatment of infections caused by mycloplasmas and chlamydiae. They have special roles in the management of some serious infections such as brucellosis, actinomycosis and plague, often in combination with other antimicrobial drugs. ${ }^{20}$ Lowdose prolonged administration of tetracyclines has a record of some success in the treatment of acne vulgaris, and more assured success in the treatment of acne rosacea. Tetracycline eye ointment is useful in the treatment of chlamydial infections of the eye.

\section{Chloramphenicol}

This drug's very broad spectrum of activity ${ }^{21}$ has been severely limited by its potential to cause aplastic anaemia, even when used locally in eye drops and eye ointment. ${ }^{22}$ Its use has also been limited by bacterial resistance which was especially evident with the staphylococci. The abuse of chloramphenicol in developing countries in recent years has received much deserved criticism but little effective action. ${ }^{23}$

Chloramphenicol retains its special role in the treatment of typhoid and of Haemophilus influenzae meningitis and epiglottitis, but note that resistance in strains of Salmonella typhi ${ }^{24}$ and $H$. influenzae $e^{25}$ is a problem in some countries.

Chloramphenicol's favourable pharmacokinetics earn it a place in the combined therapy of cerebral abscess and in the blind treatment of acute bacterial meningitis (but see below).

\section{Macrolides}

Erythromycin, the first of this group, has been widely used against Gram-positive organisms such as pneumococci, streptococci and staphylococci, especially in penicillin-hypersensitive patients. Since 1975, erythromycin has been shown to be active against a number of 'new' pathogens. As it penetrates well into cells, ${ }^{26}$ it is the drug of choice to treat chlamydial infections. It is very active against Legionella pneumophila in vitro and is recommended for treatment of legionellosis as it accumulates in leucocytes and other phagocytes and can suppress the multiplication of intracellular legionellae. ${ }^{27}$ In a guinea-pig model of legionellosis, erythromycin prevented death from the infection, but only rifampicin could clear the pathogens from the lungs and accelerate resolution. ${ }^{28}$ Malmborg ${ }^{29}$ suggested that the 2 drugs are synergistic and should be used in combination for the treatment of serious legionella infections.

Erythromycin has been shown to be active in vitro against most strains of Campylobacter jejuni and to clear the organism rapidly from stools; it does not influence the clinical outcome if given more than 5 days after the onset of illness. ${ }^{30}$

Although erythromycin is a safe drug, it produces gastro-intestinal side effects and is rather variably absorbed from the gut. Since 1975 , several new macrolides have been developed (see Table I). Their comparative in vitro properties were reviewed in 1988 by Hardy et al. ${ }^{31}$

In general, the activity of the 14-membered macrolides equals or exceeds that of erythromycin, whereas the 15 -membered azithromycin is less active against Gram-positive but more active against Gram-negative bacteria. The 16-membered macrolides are less active than erythromycin. Clarithromycin is the most active compound against Steptococcus pyogenes, pneumococci, Listeria monocytogenes and Corynebacterium spp., and it shows promising activity against Mycobacterium avium. Miocamycin, clarithromycin and rokitamycin are the most active compounds against $L$. pneomophila. Azithromycin is the most active compound against Moraxella catarrhalis, Neisseria gonorrhoeae, and Haemophilus influenzae.

Bernstein, Roudier and Fleurette ${ }^{32}$ tested several macrolides against Legionella spp. on charcoal-free media to avoid inactivation of antibiotics by charcoal and found that the most active agents were josamycin $(0.06-0,25 \mathrm{mg} / \mathrm{l})$, pristinamycin $(0.06-0.5 \mathrm{mg} / \mathrm{l})$ and erythromycin $(0.12-0.5 \mathrm{mg} / \mathrm{l})$.

Clarithromycin is an acid-stable 14-membered macrolide that achieves higher serum levels than erythromycin and has twice the serum half-life.$^{33}$ In general, the MIC's for common respiratory pathogens are 2-4-fold less than those of eryth-

Table I New macrolides

\begin{tabular}{lll}
\hline $\begin{array}{l}\text { 14-membered } \\
\text { macrolides }\end{array}$ & 15 -membered & 16-membered \\
\hline Erythromycin & Azithromycin & $\begin{array}{l}\text { Spiramycin } \\
\text { Josamycin }\end{array}$ \\
A-62671 & & Miocamycin \\
Flurithromycin & & Rokitamycin \\
Roxithromycin & & \\
\hline
\end{tabular}

From Hardy et al. (1988). ${ }^{31}$ 
romycin. Against Haemophilus influenzae the MIC's of clarithyromycin are higher than those of erythromycin, yet clarithromycin is more active in animal models. This may be explained by the recent finding that the activity of clarithromycin against $H$. influenzae appears to be enhanced by its major metabolite, 14-hydroxy-clarithromycin.

\section{Fusidic acid}

This steroid-like compound has clinically useful activity against staphylococci. As any large population of staphylococci is likely to contain mutants resistant to fusidic acid, the drug is usually given along with a penicillin or some other antibiotic to suppress their emergence during therapy. ${ }^{34}$

\section{Rifamycins}

Rifampicin, the original member of this class to be used therapeutically, has for many years been the cornerstone of multi-drug regimens for the treatment of tuberculosis. More recently, it has been used for the prophylaxis of meningococcal infection and treatment of carriers (but see later in this paper), and for the treatment of severe legionella infection in combination with erythromycin. It is also of use for the prophylaxis of Haemophilus influenzae meningitis among those exposed to this infection (see Fleming). ${ }^{35}$

The increasing problem of mycobacterial infections in acquired immunodeficiency syndrome (AIDS) patients, often with rifampicin-resistant species such as Mycobacterium avium, led to a search for more active rifamycin derivatives. Dickinson and Mitchison ${ }^{36}$ reported that rifabutin and rifapentine showed good in vitro activity against strains of the $M$. avium complex. Other workers have shown rifabutin to be more active in vitro than rifampicin, especially against $M$. avium strain $^{37,38}$ and to show synergy with ethambutol against some of them. ${ }^{39}$ However, it has been suggested that rifabutin does not have any advantages over rifampicin in practice. ${ }^{40}$ Clinical trials of the two compounds in this context are urgently needed.

So far, rifapentine is not available for clinical use. Other rifamycin derivatives have been synthesized $^{41}$ and a preliminary report suggests that some may merit further study.

\section{Metronidazole and other nitro-imidazole drugs (Tinidazole, Ornidazole, Nimorazole etc.)}

Metronidazole and other nitro-imidazole analogues have proved to be remarkably effective anti-anaerobe drugs. ${ }^{42}$ Their action depends on a potent reducing step and they are consequently largely ineffective against aerobic or facultative anaerobic organisms. They have been used for years against Trichomonas vaginalis and against Entamoeba histolytica and they now have another established role against a range of anaerobic bacterial infections from periodontal infections caused by bacteroides and fusobacterial organisms, to post-operative wound infections that have an anaerobic component. It is increasingly recognized that many infections are polymicrobial, involving two or more pathogens, and that a component of these is often anaerobic. The concept of pathogenic synergy has been greatly advanced in recent years, and the inclusion of an anti-anaerobe drug in therapeutic or prophylactic strategy has become accepted practice under various circumstances (q.v.).

Metronidazole has clinically useful activity against all obligate anaerobes, including pathogenic clostridia, bacteroides, fusobacteria and anaerobic cocci. Anaerobic fuso-spirochaetal infections respond to metronidazole. The drug has an assured place in peroperative antimicrobial prophylactic regimens when anaerobic challenges are likely, as in abdominal and pelvic surgery.

The drug's pharmacokinetic profile is good, with effective concentrations achieved in most tissues and body fluids after oral, rectal or intravenous administration. The drug's half-life is about $8 \mathrm{~h}$. It penetrates tissue well and is active in the presence of pus. Although the drug has been used widely, resistance has not been a problem; ${ }^{43}$ false evidence of metronidazole resistance in anaerobes is sometimes attributable to imperfect anaerobic technique in the laboratory and the growth of oxygentolerant isolates that are not sensitive. Some campylobacter strains and some helicobacters are sensitive to the nitroimidazoles, despite their microaerophilic nature, and this is also true for Gardnerella vaginalis. ${ }^{44}$ At present, we do not understand this.

Metronidazole is potentially irritant on intravenous injection and may cause phlebitis. Neuropathy has been reported as a possible untoward effect after prolonged high dosage. Nausea and mild gastrointestinal upsets have been noted as side effects, and skin rashes and leucopenia are listed as rare adverse reactions. Patients must be warned to avoid alcohol when taking nitro-imidazole drugs.

\section{Quinolones}

These synthetic compounds are derived from nalidixic acid which has been used as a urinary antimicrobial agent for many years. Nalidixic acid is given orally and achieves good levels in the urine but low serum levels, so that its use is limited to the prophylaxis and treatment of urinary tract infec- 
tions. Its spectrum of activity includes Gramnegative urinary tract pathogens such as Escherichia coli and Proteus spp., but the drug has poor or insignificant activity against staphylococci, enterococci and pseudomonas organisms.

Interest in the quinolones was revived with the development of 6-fluoro-7-piperazino-4-quinolones (commonly designated the 4-quinolones) that have greatly enhanced potency, wider spectra of in vitro activity and much better pharmacokinetics. ${ }^{45}$ The range of 4-quinolones continues to be extended.

The first of the new quinolones to be marketed in the UK, though not the first to be developed, was ciprofloxacin, ${ }^{46}$ a compound with extremely good activity against a wide range of Gram-negative bacteria including Pseudomonas aeruginosa, Salmonella and Shigella spp. and many Gram-positive organisms including enterococci and staphylococci. ${ }^{47}$ Its very good activity against neisseriae (Table II), notably $N$. gonorrhoeae, has allowed it to be recommended as a single-dose treatment for gonorrhoea, including that due to penicillinaseproducing strains. It is less effective against streptococci, including Strept. pneumoniae, and it is not generally recommended for the treatment of streptococcal infections or pneumococcal pneumonia. Ciprofloxacin also has useful activity against some strains of mycobacteria, ${ }^{48}$ but its activity against anaerobes is inconsistent. ${ }^{49}$ As ciprofloxacin achieves good serum and tissue levels and can be given by injection, it can be used for the treatment of systemic infections as well as gonorrhoea and urinary tract infections.

Norfloxacin has a similar spectrum of activity,,$^{50}$ but it is less potent and, as it achieves lower tissue levels, it is used predominantly as a urinary antimicrobial.

The 4-quinolones act by inhibiting bacterial DNA gyrase required for supercoiling of DNA. ${ }^{51}$ Resistance to these drugs has been reviewed by Lewin; $;^{52}$ the main mechanism of resistance is mutation in the target enzyme, but Lewin raises the possibility that plasmid-mediated resistance may occur in the future. He observed that clinically important resistance to the 4-quinolones is still relatively uncommon, though it is well known to occur in Pseudomonas aeruginosa and in staphylococci. As cross-resistance occurs among the 4-quinolones, the development of resistance to one of the series prejudices the use of any of the others against the resistant organism.

Recognized toxic reactions to the 4-quinolones are mainly confined to skin rashes, but there have been occasional reports of neurological disturbances. Interference with cartilage development noted in the joints of young dogs given ciprofloxacin has led to a reluctance to use the compounds in pregnancy or for young children.

Table II The comparative in vitro activity of ciprofloxacin, norfloxacin and nalidixic acid

\begin{tabular}{lllll}
\hline $\begin{array}{l}\text { Organism (no. of } \\
\text { isolates) }\end{array}$ & Antibiotics & Range & $M I C_{50}{ }^{*}$ & $M I C_{90}{ }^{*}$ \\
\hline Enterobacteriaceae† & Ciprofloxacin & $0.004-4$ & 0.03 & 0.12 \\
(375) & Norfloxacin & $0.016-8$ & 0.06 & 0.05 \\
& Nalidixic acid & $1->512$ & 4 & 64 \\
Ps. aeruginosa (35) & Ciprofloxacin & $0.06-1$ & 0.12 & 0.5 \\
& Norfloxacin & $0.25-4$ & 0.5 & 2 \\
& Nalidixic acid & $64->512$ & 64 & $>512$ \\
N. gonorrhoeae (55) & Ciprofloxacin & $0.001-0.004$ & 0.002 & 0.002 \\
& Norfloxacin & $0.008-0.03$ & 0.016 & 0.016 \\
& Nalidixic acid & $0.5-2$ & 1 & 2 \\
Staph. aureus (30) & Ciprofloxacin & $0.12-2$ & 0.25 & 0.5 \\
& Norfloxacin & $0.25-4$ & 1 & 2 \\
& Nalidixic acid & $32-128$ & 64 & 64 \\
Enterococci (20) & Ciprofloxacin & $0.5-2$ & 1 & 2 \\
& Norfloxacin & $2-4$ & 4 & 8 \\
& Nalidixic acid & $>512$ & $>512$ & $>512$ \\
Str. pneumoniae (19) & Ciprofloxacin & $0.5-2$ & 1 & 2 \\
& Norfloxacin & $4-16$ & 8 & 16 \\
& Nalidixic acid & $128->512$ & $>512$ & $>512$ \\
\hline
\end{tabular}

*MIC (mg/l); †includes E. coli, Klebsiella spp, Proteus spp, Serratia spp, Enterobacter spp. and Citrobacter spp.

Data from King, Shannon \& Phillips (1984). ${ }^{47}$ 
Evidence to reassure us on this point is accumulating and an authoritative assessment would be very helpful.

In addition to norfloxacin and ciprofloxacin, the range of 4-quinolones includes ofloxacin, pefloxacin, fleroxacin and enoxacin which have similar antibacterial activities and different pharmacokinetics. More recent developments with improved activity against Gram-positive organisms include WIN $57273,{ }^{53}$ and with activity against anaerobes include WIN 57273, sparfloxacin $^{54}$ and clinfloxacin (PD 127,391). ${ }^{55}$ Sparfloxacin also appears to have improved activity against mycobacteria ${ }^{56}$ Lomefloxacin has a wide range of activity against Gram-negative bacteria including multiresistant strains and Pseudomonas spp. ${ }^{57}$

\section{New challenges and changes in concept and practice}

Limitations of space oblige us to be selective in this review of our changing use of antibiotics.

\section{Dosage strategy}

Our standard teaching on the antibiotic management of an acute infection has been to give a full course of an effective antimicrobial drug at an appropriate dosage. In some cases, there is a trend away from this dogma. For example, it is standard practice now to give a short sharp course of a suitable drug to treat an acute primary urinary infection. In general, however, the principle of 'strong enough for long enough' still holds. The dosage and duration of therapy has been advocated in some detail for special cases and circumstances. One of the disadvantages of the clinician's awareness of the potential toxicity of drugs is that some antibiotics are given in sub-optimal dosage. This merits special attention with aminoglycoside therapy in which peak and trough levels must be monitored to ensure not only that toxic overdosage is avoided but that underdosage does not occur. ${ }^{11}$

\section{Prophylaxis and suppression of infection}

We have become more permissive in our approaches to the borderland of prophylaxis, suppression and treatment of infection. The antibacterial protection of patients at risk from bacterial endocarditis while undergoing dental treatment or other clinical procedures is very well established, with clear guidelines. ${ }^{58}$ The suppression of infection by the periodic or long-term use of an antibacterial drug is accepted, with proper clinical surveillance, in a range of conditions from recurrent cystitis in sexually active women ${ }^{59}$ to potentially damaging pyelonephritis in young children. ${ }^{60}$

\section{Peroperative antimicrobial prophylaxis}

The advantages of a short-term preventive ap proach have been clearly evident in surgical practice. Several bacterial challenges can be anticipated in a range of surgical procedures such as maxillofacial, abdominal or pelvic operations in which there is contamination with oropharyngeal, intestinal or vaginal flora. Antibiotic prophylaxis given at induction of anaesthesia and covering the period of the operation (hence peroperative) has significantly reduced morbidity and mortality in these circumstances. ${ }^{61-63}$ The issue of failed antibiotic prophylaxis is reviewed in a recent editorial. $^{64}$

\section{New infective challenges}

In the last 2 decades we have become aware of some new pathogens and we have recognized some old enemies in changed circumstances. Thus, the range of organisms associated with atypical pneumonias presently includes a recognized group of agents (see below) and others that may or may not be embraced by the term, depending upon the narrow- $\Omega$ ness or breadth of its interpretation, but the patient with a pneumonia that does not present typicallyo will have reason to thank the clinician who is not? blinkered by the niceties of terminology.

\section{Atypical pneumonia}

The term atypical pneumonia (originally a radiological description) is now usually used to describe pulmonary consolidation of uncertain aetiology, or from which 'conventional' bacteriological cultures have failed to reveal an obvious pathogen. In recent years the main causes of atypical pneumonia have been mycoplasmas, legionellae, chlamydiae and Coxiella burnetii.

Mycoplasmas can cause a variety of human infections but only $M$. pneumoniae causes respiratory infection. Respiratory infection with this organism is world-wide in distribution, occurring in late summer and autumn. It is thought that in the USA $M$. pneumoniae infects about $6 \%$ of the population annually. ${ }^{65}$ Epidemic peaks are well recognized. In general, the organism causes mild respiratory-tract symptoms but more serious infections can occur, especially in children, with patchy consolidation that is sometimes bilateral. Symptoms and X-ray changes may persist for several weeks, with frequent relapses. Although the infection is rarely fatal, respiratory impairment may persist for some months, especially in adults.

Legionnaire's disease, first described in $1976,{ }^{66}$ is 
a serious form of pneumonia, usually caused by Legionella pneumophila. Those especially at risk include alcoholics, diabetics, smokers, patients on immuno-suppressive therapy and those with preexisting lung disease. The disease may progress to involve virtually every organ of the body and carries an appreciable mortality. Although most cases are sporadic, several well-described outbreaks have occurred in association with hot-water systems, air-conditioning systems, cooling towers and other water systems. A study by Macfarlane $e t$ $a l .{ }^{67}$ in the Nottingham area indicated that the organism was responsible for up to $15 \%$ of cases of pneumonia, but a repeat study ${ }^{68}$ suggested that the figure then was nearer $5 \%$.

The best recognized chlamydial infection is psittacosis, caused by $C$. psittacii. Although classically associated with parrots, the infection may be acquired from a wide variety of species of birds that have included ducks and fulmar petrels. It is now accepted that most species of birds can excrete the organisms. ${ }^{69}$ Infection is acquired by the respiratory route and some strains are highly infectious so that brief contact with an infected bird may be sufficient to ensure infection. Person-to-person spread, although described, is rare. Psittacosis may present abruptly with fevers, rigors and headache. Although there are few respiratory signs or symptoms, there is often radiological evidence of extensive pneumonitis. In severe cases, the infection may involve the liver, central nervous system and myocardium, with an appreciable mortality rate.

In recent years, another species of chlamydia, $C$. pneumoniae $^{70}$ has been recognized as a cause of respiratory tract infection, usually presenting as bronchitis or pneumonia with similar clinical features to those caused by $M$. pneumoniae.

$\mathrm{Q}$ fever, caused by Coxiella burnetii is a potentially serious infection that can affect many different systems, including the respiratory tract. Although many cases are self-limiting, in serious cases the disease may affect a wide variety of systems including the lungs, with up to $50 \%$ having radiological signs of pneumonia. Chronic infection is well recognized as a cause of 'culture-negative' endocarditis. The infection is spread by inhalation of aerosols from infected sheep, goats or cattle, or by ingestion of infected unpasteurized milk. Person-to-person spread is rare but laboratoryacquired infection is well recognized in workers handling infected material.

Treatment The atypical pneumonias do not respond to the normal antibiotics given for respiratory tract infections (usually beta-lactams). $Q$ fever responds to tetracyclines, notably oxytetracycline; rifampicin and trimethoprim may be useful alternatives. ${ }^{71}$ Erythromycin is effective, as are the tetracyclines, against mycoplasmas and chlamydial infections, while erythromycin is an effective drug against legionellae, supplemented by rifampicin in severe cases. The fluoroquinolones showed promise of efficacy against mycoplasmas and legionellae but their activity has not so far been confirmed in clinical trials.

\section{Gastro-intestinal and intestinal infections}

These continue to include the well-known classics of bacillary dysentery, salmonella food poisoning and an extending range of food-borne intoxications and infections, typhoid fever and related enteric fevers, and giardiasis. The clinician has had to contend with a widening spectrum from rotavirus infections, all of the variations of enteropathogenic Escherichia coli, yersiniosis and listeriosis, to campylobacter gastroenteritis and colitis, antibiotic-associated diarrhoea and pseudomembranous colitis, and the now established role of Helicobacter pylori in relation to peptic ulcer.

When this review was written in 1991, antibiotics had a limited role in the clinical management of intestinal infections but some useful applications are recognized.

Metronidazole has earned its place in the therapy of entamoeba infections and giardiasis. Erythromycin can help in the management of campylobacter gastro-enteritis or colitis, but the indications for its use are not yet clearly drawn; parenteral gentamicin may be used for severe septicaemic cases. Vancomycin is established as the preferred agent for therapy of pseudomembranous colitis, while metronidazole is generally regarded as a second option.

Chloramphenicol seems to retain its place as the first choice for the treatment of the enteric fevers (typhoid and paratyphoid), though some typhoid bacilli are resistant and other factors merit consideration. ${ }^{24,72}$ Chloramphenicol's place is challenged by amoxycillin or cotrimoxazole or trimethoprim which may, in turn, be replaced by ciprofloxacin or by one of the third or fourth generation cephalosporins if these latter drugs stand the test of time and comparative trials. Success has also been claimed for pivmecillinam and moxalactam. It is clear that a clinician with responsibilities in this difficult field needs very competent microbiological support to advise on local patterns of resistance and to monitor excretion and carrier rates during and after therapy and relapse rates. ${ }^{24,72}$

Specific antibacterial treatment has not been generally recommended for other salmonella infections or for shigella infections of the gut, but severe invasive or toxic infections may demand specific therapy. The choice of drug is very difficult because resistance is so common. With the development of 
the quinolones, notably ciprofloxacin, our approaches to treatment merit reappraisal and perhaps modification. Note, however, that resistance to the quinolones is already occurring.

Diarrhoeagenic strains of Escherichia coli that produce the vero cytotoxin (VTEC) are associated with haemorrhagic colitis and a haemolytic uraemic syndrome. The serogroup is commonly 0157. The increasingly complex subject of Escherichia coli diarrhoea has been most competently reviewed by Gross ${ }^{73}$ who points out that rehydration of the patient must be the first priority.

The antimicrobial treatment of cholera cannot displace the life-saving priority of the active replacement of fluid and electrolytes, but tetracycline $0.5 \mathrm{~g}$ given 6 -hourly for $72 \mathrm{~h}$ reduces the excretion of live vibrios and moderates the diarrhoea. The spread of cholera can be moderated by giving a daily dose of prophylactic tetracycline $1 \mathrm{~g}$ for 5 days to family contacts at risk. ${ }^{74}$

The occurrence of tetracycline resistance is common in areas where the drug has been widely used to control cholera.

Helicobacter pylori predisposes to peptic ulceration and may be controlled or eradicated by treatment with bismuth subcitrate or subsalicylate, amoxycillin and metronidazole singly or in a combined schedule. ${ }^{75}$

Travellers' diarrhoea This causes much anxiety and inconvenience. ${ }^{76}$ It is variously ascribed to infection with campylobacters, enterotoxigenic Escherichia coli (ETEC), ${ }^{73}$ sometimes salmonellae or shigellae, and sometimes various viruses including small round viruses and the Norwalk virus. An association between Norwalk virus, water supplies and cruise ships is noted in the textbooks. Thus, the microbiology is complex and recommendations for active prophylaxis range widely and sometimes wildly. Turnberg ${ }^{76}$ has summarized the present situation well.

It is difficult to come off the fence in such contested territory. At a recent symposium, an experienced traveller and observer discussed the relative merits of a daily dose of doxycycline $100 \mathrm{mg}$, or cotrimoxazole $960 \mathrm{mg}$, or norfloxacin $400 \mathrm{mg}$ for the prevention of travellers' diarrhoea. On balance, norfloxacin got his vote. Microbiological writers must add the caution that many may regard this as the abuse of an important drug, while they discreetly note the recommendation for their private consideration.

\section{Polymicrobial infections}

The antibacterial approach to our therapy of many soft-tissue infections ranging from dental abscess to pelvic inflammatory disease has been revolutionized by awareness that many of these infections are polymicrobial and that some have a significant anaerobic element (see Table III). ${ }^{77}$ Accordingly, metronidazole is now established as a necessary component of the treatment of such infections in hospital and in general practice. ${ }^{43}$

\section{Cerebral abscess}

This provides an illustrative example of a condition that may be a mixed infection with anaerobes and facultative organisms.

In recent years, our evolving understanding of the infecting organisms involved in cerebral abscesses has allowed a more rational approach to therapy. De Louvois, Gortvai and Hurley ${ }^{78,79}$ believed that cerebral abscesses of sinusitic origin were generally frontal and yielded penicillinsensitive streptococci, notably $S$. milleri, whereas abscesses derived from an otitis media were usually temporal and polymicrobial with an anaerobic component. Ingham, Selkon and Roxby ${ }^{80}$ agreed that many cerebral abscesses are of otitic origin, with Bacteroides fragilis as the predominant anaerobe, but Ingham et al ${ }^{81}$ went on to point out that many frontal abscesses may be derived from dental sepsis and would consequently involve anaerobes as well as facultative organisms. Thus metronidazole gained an established place in the antimicrobial management of cerebral abscess, and

Table III Conditions in which there is often a polymicrobial infection with a significant anaerobic component

Cerebral abscess
Dental abscess
Periodontal disease
Human and animal bite wounds
Paronychia
Acute necrotizing ulcerative gingivitis (Vincent's infection)
Cancrum oris
Oropharyngeal sepsis, including Ludwig's angina
Post-operative infection after maxillo-facial tumour surgery
Chronic otitis media
Some cases of sinusitis
Dermal gangrene
Necrotizing fasciitis
Necrobacillosis, including Lemierre's disease, Fournier's
gangrene, etc.
Lung abscess, bronchiectasis and aspiration pneumonia
Post-operative peritonitis (and post-perforation
peritonitis, especially involving the large bowel)
Peri-anal abscess
Pelvic abscess
Pelvic inflammatory disease
Vaginosis
Balano-posthitis
Gas gangrene
Bedsores
Foot ulcers in patients with diabetes

Cerebral abscess

Periodontal disease

Paronychia

Acute necrotizing ulcerative gingivitis (Vincent's infection)

Cancrum oris

Oropharyngeal sepsis, including Ludwig's angina

Chronic otitis media

Some cases of sinusitis

Dermal gangrene

Necrotizing fasciitis

(ecrobacillosis, including Lemierre's disease, Fournier's

Lung abscess, bronchiectasis and aspiration pneumonia peritonitis (and post-perforation peritonitis, especially involving the large bowel)

Pelvic inflammatory disease

Vaginosis

Balano-posthitis

Bedsores

Foot ulcers in patients with diabetes 
the benefit of this progressive step was quickly evident. ${ }^{82,83}$

\section{Acute bacterial meningitis}

The specific antimicrobial treatment of acute purulent meningitis varies with the causative organism, if it is known. Clinicians in the UK recognize that the league leaders are the meningococcus and Haemophilus influenzae and that the age of the patient must be considered in assessing the possible infective agent. Thus, neonatal meningitis is likely to be caused by Escherichia coli or a Group B streptococcus.

It is important to check the sensitivity of the strain involved. As resistance to ampicillin is not uncommon in $H$. influenzae, chloramphenicol has a special role here. We watch with concern the occurrence of chloramphenicol resistance in haemophilus bacteria in some countries. Penicillin or chloramphenicol are generally used for the treatment of meningococcal meningitis. Penicillin is the drug of choice for the treatment of pneumococcal meningitis. Penicillin-resistant pneumococci are well known to occur in some parts of the world. Even when the strain is fully sensitive to penicillin, it is acknowledged that the results of treatment of pneumococcal meningitis may be disappointing.

The initial blind therapy for a patient with acute purulent meningitis takes account of the likely causes and may include chloramphenicol and penicillin. Some clinicians now favour the use of cefotaxime or ceftriaxone. The subject is very well reviewed by Ispahani. ${ }^{84}$

\section{Prophylaxis of contacts of acute bacterial meningitis}

Until the development of sulphonamide resistance in meningococci, the prophylaxis of close contacts of a case of meningococcal meningitis was straightforward. As penicillin does not eliminate meningococci from the nasopharynx, a short course of rifampicin or minocycline was chosen to deal with the carrier state. Minocycline has some disadvantages and rifampicin became established in the preventive role. ${ }^{85}$

There are good reasons to regard ciprofloxacin as a preferred alternative, because rifampicin has so many other important uses and should be protected. However, the people to be protected often include young children and there is some reluctance to give ciprofloxacin to young children. The giving of a short course may well be justified, but there is no authoritative pronouncement to date.

Meanwhile, the concept of prophylaxis has changed. An important difference has been recog- nized between the early colonization that represents an incipient infection ('co-primary infection') and the established carrier state. ${ }^{86}$ In the former situation, a course of penicillin would abort the attack as it is being mounted. This action would be reasonable for the immediate protection of the close contacts of a case of meningococcal meningitis and it is now established practice in Norway. In Britain, rifampicin is still the standard prophylactic in this context and (at different dosage) we are beginning to follow accepted US practice in regarding rifampicin as the recommended antibiotic for the protection of close contacts of Haemophilus influenzae meningitis. ${ }^{87}$

\section{Chlamydial infections}

Chlamydiae cause infections of the eye, the genital tract and adnexa, and the respiratory tract. As these organisms also cause infections in animals, there may be an occupational link in some cases (e.g. farmers, veterinary workers, abattoir workers, owners of pets). Laboratory diagnosis has improved in recent years. Therapeutic options have widened to include erythromycin, tetracyclines, and the quinolones - although the early promise of the latter has still to be realized. Newer quinolone derivatives may give better results, but erythromycin is the first-line choice and the tetracyclines are close alternatives.

Pelvic inflammatory disease occurs in women as a result of an ascending infection in the genital tract with endometritis, salpingitis and salpingo-oophoritis. There is a strong association with sexual intercourse and it is thought that spermatozoa may act as carriers that allow non-motile potential pathogens to gain access to the upper genital tract. A mixed infection often occurs in which gonococci or chlamydiae (or both) may be present with aerobic or anaerobic organisms. The anaerobic component often includes bacteroides organisms. Accordingly, treatment with a single antibiotic is unlikely to be effective. Careful investigation and combination therapy are essential.

This subject was authoritatively reviewed by Pearce ${ }^{88}$ who considered that treatment with parenteral antibiotics should include a single dose of ampicillin and probenecid to control gonorrhoea; a 1-week course of gentamicin or a second generation cephalosporin to deal with coliform opportunists; a 2-week course of metronidazole to eradicate anaerobes; and a 2-week follow-up course of doxycycline or erythromycin to eradicate chlamydiae. We sympathize with the patient confronted with such a regimen, but we have to call attention to the many failures and all of the morbidity that have attended less thorough approaches to the therapy of this distressing condition. 


\section{Compromised hosts}

The term is now used too loosely and our experience of opportunistic infections in the last 10 years teaches us to be more specific and more discriminating. It may be said that any infective pathogen is opportunistic, taking advantage of circumstances and special sets of variables in the host-parasite relationship to express aggression and virulence. It is increasingly recognized that certain forms of compromise are associated with known ranges of potential infections. Thus, for example, foreign bodies and prostheses inserted into tissues may act as foci for infection with Gram-positive cocci, diphtheroid organisms or yeasts, whereas neutropenic patients are at special risk of generalized infections with coliform organisms or cocci (see below).

Patients who have inadequate spleens (hyposplenism) or who have lost their spleens as a result of operative removal after injury or for therapeutic reasons, are vulnerable to overwhelming infection with pneumococci and some other pathogens that include Pseudomonas aeruginosa and Capnocytophaga canimorsus. ${ }^{89}$ As functional hyposplenism is known to occur in sickle-cell anaemia, coeliac disease and bone-marrow transplant recipients, clinicians must be vigilant.

The reader is referred to a succinct reminder of the range of patients who may be chronically immunodeficient as a result of diseases ranging from diabetes mellitus to AIDS. ${ }^{90}$

The prevention of pneumococcal infections in those at special risk rests primarily upon awareness of the individual's susceptibility which must be clearly recorded. Pneumococcal vaccine affords some protection, but not for young children aged less than 2 years. As the protection afforded lasts for about 5 years, and as revaccination is not currently advised, ${ }^{91}$ it is difficult to make a clear recommendation. The prompt prophylactic use of amoxycillin for a patient in the risk group who develops signs of an infective illness is perhaps a more defined and positive approach.

\section{Antibiotic cover for transient neutropenia}

In the last decade, the provision of antibiotic cover to protect a patient whose defences are temporarily suppressed has become fairly standard practice. Opinions vary on the specific drugs used and the indications for their use.

Most clinicians agree that a patient under treatment for leukaemia with cytotoxic chemotherapy or irradiation should have the benefit of antimicrobial drugs to provide a bridge over the troubled waters of their vulnerability while their granulocyte counts are abnormally low. ${ }^{92}$ Currently favoured regimens take account of the successive reports of the
European Organisation for Research on Treatment of Cancer (EORTC) Antimicrobial Therapy Cooperative Group ${ }^{93,94}$ and the views of other experienced workers. ${ }^{11,95,96}$ The use of monotherapy in neutropenia is often enthusiastically advocated, but the evidence suggests that the established drug combinations have advantages against the continuing evolution of bacterial drug resistance.

\section{Prevention of infection in patients in intensive care} units

The principle of a selective parenteral and enteral antisepsis regimen (SPEAR) ${ }^{97}$ is an extension of the concept of selective decontamination of the gut (q.v.) to prevent superinfection in severely injured patients ${ }^{98-100}$ Promising claims are being made and this approach merits further study and cautious application, with special attention to the drug resistance profiles of the bacterial pathogens encountered.

\section{Antibiotic-associated diarrhoea and pseudomembranous colitis}

Adverse reactions to antibiotics include gastro intestinal upsets and diarrhoea. Antibiotic-assoce iated diarrhoea is quite common and is usually self-limiting, stopping when the course of antibiotic is completed. In some cases, severe diarrhoea necessitates premature withdrawal of the provoking antibiotic. It has become increasingly recognized that some antibiotics are more likely than others to upset the normal bowel flora and to render the bowel more vulnerable to invasion and overgrowth by potential pathogens. The concept of the colonization resistance of the normal bowel as a function of its normal flora was advanced by Van der Waaij and colleagues. ${ }^{101}$ These workers advocate the classification of antibiotics into 3 groups: (1) those that markedly alter the bowel flora and suppress colonization resistance, such as ampicillin and some other penicillin derivatives; (2) those that are intermediate in this context, such as the aminoglycosides and some parenteral cephalosporins and (3) those that are 'indifferent' and exert no effect on colonization resistance, such as cephradine and cotrimoxazole.

Loss of colonization resistance and overgrowth with other organisms is worrying, because potential pathogens may be enriched and resistance transfer may be encouraged within and between the new populations of organisms. Clostridium difficile is one of special concern. If this organism is enriched in the bowel, it produces a range of toxins and gives rise to pseudomembranous colitis which is potentially fatal. ${ }^{102}$ If $C$. difficile or its cytopathic toxin is identified in the stools of a patient with 
antibiotic-associated diarrhoea, this calls for immediate cessation of the provoking antibiotic therapy and the administration of vancomycin to control the condition. In some cases, despite vancomycin therapy, the condition recurs.

\section{Line infections}

The increasing use of implanted materials in medicine and surgery carries associated risks of infection. Prosthetic joints carry a well-recognized risk of infection, often necessitating removal of the prosthesis. ${ }^{103}$ Such infections are often due to 'low-grade' pathogens and become apparent weeks after the operation. Similarly, cardiac pacemakers may be associated with localized infection, often staphylococcal, that may interfere with their proper functioning and require removal.

One of the most important sources of infection are vascular catheters, some of which may be in situ for several weeks if the patient requires total parenteral nutrition (TPN). There is good evidence that infection is more likely if the catheters are in place for long periods, if the patient is very young or if the patient is immunocompromised. The increasing use of broad-spectrum antibiotics may predispose to infection with resistant organisms.

It is well recognized that some infecting strains form a slime that is deposited on the inside of the catheter, providing a good nidus for infection. Infection is often due to Staph. epidermidis and is thought often to be derived from the skin flora. Blood cultures are frequently positive in these patients. In a recent review, the importance of prevention of catheter-associated sepsis by careful attention to aseptic procedure was stressed. Other preventive measures include intravenous heparin therapy, protection of catheter junctions, attention to details of procedure and tunnelling of catheters.

Once established, catheter-associated infections may require removal of the catheter (often this is all that is required) or the use of a systemic antibiotic such as vancomycin. Balakrishnan and colleagues pointed out ${ }^{104}$ that these infections may have important cost implications that include increased stay in hospital (usually in Intensive Care Units) and the use of expensive antibiotics such as vancomycin.

Organisms infecting catheters or other implanted devices may grow as a biofilm and create a local microenvironment. ${ }^{105}$ The features of the population may be different from those of single organisms, making them for example more resistant to antibiotics and, by production of exopolysaccharide glycocalices, more resistant to host defence mechanisms. It has been suggested that the adherence of coagulase-negative staphylococci to polystyrene or rubber is influenced both by anti- biotics and by the concentration of carbon dioxide in the environment. ${ }^{106}$

\section{Mycobacterial infections}

Notifications of tuberculosis have declined steadily in the United Kingdom, especially since the introduction of effective chemotherapy. It is generally accepted that effective chemotherapy has prevented the emergence of resistant strains of $M$. tuberculosis. Thus, at present, most if not all strains of mycobacterial infection in the United Kingdom respond to the first line antimycobacterial drugs, for example, rifampicin, isoniazid, pyrazinamide and ethambutol. Sometimes, isoniazid-resistant strains occur and we have recently described an outbreak occurring in Glasgow. ${ }^{107}$ Patients from other countries in which chemotherapy of tuberculosis is less effective may present in the UK with tuberculosis due to resistant organisms. Accordingly, it is unwise to assume that all strains of $M$. tuberculosis isolated in the UK are always fully sensitive. Sensitivity testing of all mycobacterial isolates is essential. Current recommendations for the chemotherapy of tuberculosis are set out in detail in a recent paper. ${ }^{108}$

The present epidemic of HIV infection has been associated with an increase in mycobacterial infections and the observed increase in notifications both in England and Wales and in Scotland in 1989 and 1990 may be due to this but it is likely that other factors are also responsible. Infection with $\boldsymbol{M}$. tuberculosis is a feature of the relatively early stages of HIV infection and, although tuberculosis may present abnormally in these patients (as a generalized infection with fairly non-specific lung signs) it is amenable to treatment with standard therapy. In the later stages of the disease when the patient has developed AIDS, infections with other mycobacteria, notably Mycobacterium avium, are a feature. These infections are often difficult to treat and may prove to be terminal events. It is difficult to know whether such an infection is merely a marker of a very severely depleted immune system or whether it precipitates further deterioration in immunity. There are no recognized protocols for treating these infections and individual clinicians use different drug combinations that often include amikacin, rifampicin (or rifabutin). Much work needs to be done to establish the best treatment for these mycobacterial infections.

Many of the 4-quinolones possess antimycobacterial activity. Some of the more recent ones still under development, for example, sparfloxacin, show considerable promise. ${ }^{56}$ To date there have been no formal clinical trials, but studies are to commence in some European countries in the near future. Quinolone compounds may well prove to be 
a useful addition to the therapeutic armamentarium of anti-mycobacterial drugs.

\section{Bacterial drug resistance}

This problem is unrelenting. In the last decade, we have seen penicillin resistance extending into a wide range of organisms that include Haemophilus influenzae and Neisseria gonorrhoeae ${ }^{109}$ It has been known for years that genetic information endowing bacteria with antibiotic resistance can be transferred by various mechanisms that include transduction by phage, and by conjugation which has some parallels with sexual forms of transmission. The transfer of plasmids between related bacteria allows packets of resistance information to be exchanged, and the potential harm of plasmidmediated resistance is well recognized. There are now examples of exchanges of resistance information between coliform bacteria that cross taxonomic boundaries and qualify for the description of promiscuous behaviour. These interlinked systems account for the daunting speed of the transmission of bacterial drug resistance information so that resistant strains are encountered rapidly across the world. ${ }^{110}$ This has been assisted by transposons which are small bits of DNA that are able to jump between plasmids in the same cell. ${ }^{111}$ To add further to the complexity of the scenario, it is now becoming clear that a mechanism of genetic exchange resembling transformation may account for the exchange of plasmid-borne information in coliform bacteria, while conjugation systems may operate in Gram-positive bacteria that we previously thought were unable to exchange DNA in this way.

We have had to extend our understanding of the range of pathogens that readily acquire resistance. ${ }^{112}$ In recent years we have recognized that Moraxella (Branhamella) catarrhalis is not merely a respiratory commensal but can be an important respiratory tract pathogen. ${ }^{113} M$. catarrhalis is resistant to some of the antibiotics commonly used for the treatment of respiratory tract infection, especially ampicillin/amoxycillin, due to beta-lactamase production. Over $70 \%$ of clinical isolates are beta-lactamase producing, in our experience at the City Hospital Bacteriology Laboratory, Edinburgh.

Another pathogen that may be resistant to penicillins because of beta-lactamase production is Haemophilus influenzae. A recent reviewer ${ }^{25}$ indicated that $10 \%$ of non-capsulate and $25 \%$ of type $b$ strains from blood and CSF in the UK were beta-lactamase positive. Some non-capsulate strains resistant to ampicillin (MIC $>1 \mathrm{mg} / \mathrm{l}$ ) are betalactamase negative, the mechanism of resistance being chromosomal in nature. Such strains are often resistant to several beta-lactams.
The oral cephalosporins have only moderate activity against $H$. influenzae, and $1-4 \%$ of strains in the UK and Eire were reported to be resistant to chloramphenicol. ${ }^{114,115}$ Injectable cephalosporins such as cefotaxime, aztreonam, the penems or the 4-quinolones are all suggested by Powell as useful drugs in the treatment of serious infections caused by ampicillin-resistant strains of $\boldsymbol{H}$. influenzae.

By 1988 , bacterial strains resistant to thirdgeneration cephalosporins were being encountered across the world and many observers expressed alarm. ${ }^{116}$ As these drugs were increasingly used, various opportunist pathogens acquired resistance and added significantly to the gene pool of resistance information. Bergogne-Berezin and JolyGuillon $^{117}$ drew special attention to acinetobacter organisms and their potential danger in hospital. We were already aware of the problems posed by klebsiellae and enterobacters and many other opportunists in this context. Reports from various countries provided strangely conflicting evidence of bacterial drug resistance. ${ }^{116}$ It is essential to develop better surveillance and reporting systems if we are to control or moderate the threat to all of our antimicrobial drugs. The staphylococcus provides a frightening illustrative example.

\section{Methicillin-resistant Staph. aureus (MRSA)}

The first reports of resistance to methicillin in? staphylococci appeared soon after the introduction of the drug in 1959. Although sporadic outbreaks of infection due to these organisms occurred, it was not until the 1980s that they posed significant problems in the UK and elsewhere ${ }^{118}$ in relation to hospital infection control.

Some strains are more transmissible than others ('epidemic methicillin-resistant Staph. aureus' EMRSA). ${ }^{119}$ Such strains often belong to a single phage group although many are untypable by standard phages. Most MRSA strains have a special ability to colonize skin and anterior nares and to spread from person to person, though they are not more virulent than methicillin-sensitive strains. The problems that they pose relate to control of spread of infection and to treatment of established infections, when methicillin and flucloxacillin are inactive.

Spread of infection has to be controlled or prevented by rigorous control of infection measures such as those laid down by the Joint Working Party of the Hospital Infection Society and British Society for Antimicrobial Chemotherapy. ${ }^{120}$ In addition, the development of mupirocin (a pseudomonic acid) as a topical specific anti-staphylococcal agent has enabled efforts to be made to eradicate nasal and skin carriage by applying mupirocin ointment and 
mupirocin in a polyethylene glycol base respectively.

Treatment of established infections may be diffcult, as strains of MRSA are usually resistant to gentamicin and chloramphenicol as well as to methicillin and flucloxacillin. Many authorities suggest vancomycin, alone or in combination with rifampicin. ${ }^{118-120}$ Newer agents such as teicoplanin a glycopeptide antibiotic with similar activity to

\section{References}

\section{The basic armament}

1. Williams, J.D. Antimicrobial substances used in the treatment of infections. In: Linton, A.H. \& Dick, H.M. (eds) Topley \& Wilson's Bacteriology, Virology and Immunity, 8th ed, Vol.1, chapter 5. Edward Arnold, London, 1990, pp. $105-152$.

2. Anonymous. Current practice: Today's drugs. Penicillins, Benzylpenicillin. Br Med J 1963, 1: 1137-1140.

3. Bush, K., Beta-lactamase inhibitors from laboratory to clinic. Clin Microb Rev 1988, 1: 109-123.

4. Kuk, N.A., Jacobus, N.V., Petersen, P.J. et al. Comparative in vitro and in vivo activities of piperacillin combined with beta-lactamase inhibitors tazobactam, clavulanic acid and sulbactam. Antimicrob Agents Chemother 1989, 33: 1964-1969.

5. Williams, J.D. The cephalosporin antibiotics. Drugs 1987 , 34 (Suppl 2): 1-258.

6. Rubinstein, E. \& Isturiz, R. Aztreonam: the expanding clinical profile. Rev Infect Dis 1991, 13 (Suppl 7): S581-S654.

7. Clissold, S.P., Todd, P.A. \& Campoli-Richards, D.M. Imipenem/Cilastatin: A review of its antibacterial activity, pharmacokinetic properties and therapeutic efficacy. Drugs 1987, 33: 183-241.

8. Davey, P., Davies, A., Livermore, D. \& Speller, D. Meropenem (SM 7338) - a new carbapenen. $J$ Antimicrob Chemother 1989, Suppl. A, 9-29.

9. Rolinson, G.L. Beta-lactam antibiotics. J Antimicrob Chemother 1986, 17: 5-36.

10. Livermore, D.M. \& Wood, M.J. Mechanisms and clinical significance of resistance to new beta-lactam antibiotics. $\mathrm{Br} \mathrm{J}$ Hosp Med 1990, 44: 252-263.

11. Davey, P. Clinical use of the aminoglycosides in the 1990s. Rev Med Microbiol 1991, 2: 22-30.

12. Mattie, H., Craig, W.A. \& Pechere, J.C. Determinants of efficacy and toxicity of aminoglycosides. $J$ Antimicrob Chemother 1989, 24: 281-293.

13. Lovering, A.M., Bywater, M.J., Holt, H.A. et al. Resistance of bacterial pathogens to four aminoglycosides and six other antibacterials and prevalence of aminoglycoside modifying enzymes, in 20 UK centres. J Antimicrob Chemother 1988, 22: 823-839.

14. European Study Group on Antibiotic Resistance. In-vitro susceptibility to aminoglycoside antibiotics in blood and urine isolates consecutively collected in 29 European laboratories. Eur J Clin Microbiol 1987, 6: 378-385.

15. Muscato, J.J., Wilbur, D.W., Stout, J.J. \& Fahrlender, R.A. An evaluation of the susceptibility patterns of Gramnegative organisms isolated in cancer centres with aminoglycoside usage. In: Davey, P.G., Finch, R.G. \& Wood, M.J. (eds) Once Daily Amikacin. J Antimicrob Chemother 1991, 27 (Suppl. C): 1-7.

16. Hathorn, J.W. \& Pizzo, P.A. Is there a role for monotherapy with beta-lactam antibiotics in the initial empirical management of febrile neutropenic cancer patients? J Antimicrob Chemother 1986, 17 (Suppl. A): 41-54.

17. Greenwood, D. Antimicrobial Chemotherapy, 2nd ed. Oxford Medical Publications, Oxford. 1989, p. 45. vancomycin) and ciprofloxacin offer promise ${ }^{121}$ though strains of MRSA that are resistant to ciprofloxacin have been described and therapeutic failures reported. It has become clear that the presence of an implanted prosthesis or venous line may provide a nidus for continuing infection and that removal of the device may be necessary to eradicate the infection.

18. Levey, S.B. Evolution and spread of tetracycline resistance determinants. Leading article. J Antimicrob Chemother 1989, 24: $1-7$.

19. Anonymous. Tetracyclines after 25 years. $\mathrm{Br} \mathrm{Med} \mathrm{J} \mathrm{1974,} \mathrm{2:}$ 400-401.

20. Garrod, L.P., Lambert, H.P. \& O'Grady, F. Tetracyclines. In: Antibiotic and Chemotherapy, 5th ed. Churchill Livingstone, Edinburgh, 1981, pp. 169-172.

21. Smyth, E.G. \& Pallett, A.P. Clinician's guide to antibiotics. Br J Hosp Med 1988, 39: 424-428.

22. Stevens, J.D. \& Mission, G.P. Ophthalmic use of chloramphenicol. Lancet 1987, ii: 1456.

23. Collee, J.G. \& Amyes, S.G.B. Relevance of bacterial resistance for clinical and community medicine: point of view of the bacteriologist. In: Michel, M.F. \& van der Meer, J.W.M. (eds), Proceedings of the BRL Kurhaus Workshop on Antibiotics. Beecham Research Laboratories, Amstelveen, Netherlands, 1985, pp. 67-77.

24. Mandal, B.K. Modern treatment of typhoid fever. $J$ Infect 1991, 22: 1-4.

25. Powell, M. Chemotherapy for infections caused by Haemophilus influenzae: Current problems and future prospects. $J$ Antimicrob Chemother 1991, 1: 3-7.

26. Martin, J.R., Johnson, P. \& Miller, M.F. Uptake accumulation and egress of erythromycin by tissue culture cells of human origin. Antimicrob Agents and Chemother 1985, 27: 314-319.

27. Miller, M.F., Martin, J.R., Johnson, P. et al. Erythromycin uptake and accumulation by human polymorphonuclear leukocytes and efficacy of erythromycin in killing ingested Legionella pneumophila. J Infect Dis 1984, 149: 714-718.

28. Baskerville, A., Fitzgeorge, R.B., Gibson, D.H. et al. Pathological and bacteriological findings after aerosol Legionella pneumophila infection of susceptible, convalescent and antibiotic-treated animals. In: Thornsberry, C., Balows, A., Feeley, J.C. \& Jakubowski, W. (eds) Legionella. Proceedings of the Second International Symposium. American Society for Microbiology, Washington, DC, 1984, pp. 131-132.

29. Malmborg, A.S. The renaissance of erythromycin. J Antimicrob Chemother 1986, 18: 293-299.

30. Anders, B.J., Lauer, B.A., Paisley, J.W. \& Reller, L.B. Double-blind placebo controlled trial of erythromycin for treatment of campylobacter enteritis. Lancet 1982, i: $131-132$.

31. Hardy, D.J., Hensey, D.M., Beyer, J.M. et al. Comparative in vitro activities of new 14-, 15-, and 16-membered macrolides. Antimicrob Agents Chemother 1988, 32: 1710-1719.

32. Bernstein, N., Roudier, C. \& Fleurette, J. Determination of the activity against Legionella of eight macrolides and related agents by comparative testing on three media. $J$ Antimicrob Chemother 1985, 15: 17-22. 
33. Hardy, D.J., Swanson, R.N., Rode, R.A. et al. Enhancement of the in vitro and in vivo activities of clarithromycin against Haemophilus influenzae by 14-hydroxy-clarithromycin, its major metabolite in humans. Antimicrob Agents Chemother 1990, 34: 1407-1413.

34. Phillips, I. \& Spellar, D. (eds). Fusidic acid: a reappraisal. $J$ Antimicrob Chemother 1990, 25 (Suppl B): 1-60.

35. Fleming, D.W., Cochi, S.L., Hull, H.F. et al. Prevention of Haemophilus influenzae type b infections in day care: a public health perspective. Rev Infect Dis 1986, 8: 568-572.

36. Dickinson, J.M. \& Mitchison, D.A. In vitro activity of new rifamycins against rifampicin-resistant Mycobacterium tuberculosis and MAIS-complex mycobacteria. Tubercle 1987, 68: $177-182$.

37. Saito, H., Sato, K. \& Tonicoka, H. Comparable in vitro and in vivo activity of rifabutin and rifampicin against $\mathrm{Myco}$ bacterium avium complex. Tubercle 1988, 69: 187-192.

38. Heifets, L.B., Lindholm-Levy, P.J. \& Iseman, M.D. Rifabutine: minimal inhibitory and bactericidal concentrations for Mycobacterium tuberculosis. Am Rev Resp Dis 1988, 137: $719-721$.

39. Heifets, L.B., Iseman, M.D. \& Lindholm-Levy, P.J. Combinations of rifampicin or rifabutin plus ethambutol against Mycobacterium avium complex. Am Rev Resp Dis 1988, 137: $711-715$

40. Young, L.S. Mycobacterium avium complex infection. $J$ Infect Dis 1988, 157: 863-867.

41. Cavalleri, B., Turconi, M., Tamboini, G. et al. Synthesis and biological activity of some derivatives of rifamycin P. J Med Chem 1990, 33: 1470-1476.

42. Wise, R. \& Logan, M.N. Anaerobic infections and their treatment. In: Grüneberg, R.N. (ed.) Antibiotics and Chemotherapy. Current Status of Modern Therapy. MTP Press, Lancaster, 1980, vol. 4, chapter 4, pp. 113-137.

43. Greenwood, D., Watt, B. \& Duerden, B.I. Antibiotics and Anaerobes. In: Duerden, B.I. \& Drasar, B.S. (eds) Anaerobes in Human Disease. Edward Arnold, London, 1991, chapter 25, pp. 415-429.

44. Skirrow, M.B. Campylobacter, Helicobacter and other curved Gram-negative rods. In: Parker, M.T. \& Duerden, B.I. (eds) Topley \& Wilson's Bacteriology, Virology and Immunity, 8th ed, vol. 2, chapter 27. Edward Arnold, London, 1990, pp. 531-549.

45. Wolfson, J.S. \& Hooper, D.C. The fluoroquinolones: structure, mechanisms of action and resistance, and spectra of activity in vitro. Antimicrob Agents Chemother 1985, 28: $581-586$.

46. Sanders, C.C., Sanders, W.E. \& Grering, R.V. Overview of preclinical studies with ciprofloxacin. Am J Med 1987, Suppl. 4A: 2-11.

47. King, A., Shannon, K. \& Phillips, I. The in vitro activity of ciprofloxacin compared with that of norfloxacin and nalidixic acid. J Antimicrob Chemother 1984, 13: 325-331.

48. Young, L.S., Berlin, O.G.W. \& Inderlied, C.B. Activity of ciprofloxacin and other fluorinated quinolones against mycobacteria. Am J Med 1987, 82 (Suppl. 4A): 23-26.

49. Watt, B. \& Brown, F.V. Is ciprofloxacin active against clinically important anaerobes? J Antimicrob Chemother 1986, 17: 605-613.

50. Kucsers, A. \& Bennett, N.M. Norfloxacin. In: Kucsers, A. \& Bennett, N.M. (eds) The Use of Antibiotics. Heinemann Medical Books, London, 1987, pp. 1234-1241.

51. Cozzarelli, N.R. DNA gyrase and the supercoiling of DNA. Science 1980, 207: 953-960.

52. Lewin, C.S., Allen, R.B. \& Amyes, S.G.B. Potential mechanisms of resistance to the modern 4-quinolones. $\mathrm{J} \mathrm{Med}$ Microbiol 1990, 31: 153-161.

53. Kaatz, G.W. \& Seo, S.M. WIN 57273, a new fluoroquinolone with enhanced in vitro activity versus Grampositive pathogens. Antimicrob Agents Chemother 1990, 34: 1376-1380.
54. Cooper, M.A., Andrews, J.M., Ashby, J.P. et al. In vitro activity of sparfloxacin, a new quinolone agent. $J$ Antimicrob Chemother 1990, 26: 667-676.

55. King, A., Boothman, C. \& Phillips, I. The in vitro activity of PD127,391, a new quinolone. J Antimicrob Chemother 1988, 22: 135-141.

56. Yajko, D.M., Sanders, C.A., Bassos, P.S. \& Hadley, W.K. In-vitro susceptibility of Mycobacterium avium complex to the new fluoroquinolone sparfloxacin (CI-978; AT-4140) and comparison with ciprofloxacin. Antimicrob Agents Chemother 1990, 34: 2442-2444.

57. Leigh, D.A., Tait, S. \& Walsh, B. Antibacterial activity of lomefloxacin. J Antimicrob Chemother 1991, 27: 589-598.

\section{New challenges and changes in concept and practice}

58. Oakley, C.M. Treatment of infective endocarditis. Pre scribers' J 1990, 30: 152-165.

59. Brumfitt, W. \& Hamilton-Miller, J.M.T. Prophylactic antibiotics for recurrent urinary tract infections. $J$ Antimicrob Chemother 1990, 25: 505-512.

60. Smellie, J.M. \& Prescod, N. Natural history of overt urinary infection in childhood. In: Asscher, A.W. \& Brumfitt, W. (eds) Microbiological Diseases in Nephrology. John Wiley, Chichester, 1986, pp. 243-254.

61. Willis, A.T. Rationale for antimicrobial prophylaxis at surgery. Eur J Chemother Antibio 1982, 2: 87-93.

62. Goldman, L.A. (ed) A Contemporary View of Hospital Antibiotic Prophylaxis. Update Sibert Publications, London, 1987.

63. Pollock, A.V. Surgical prophylaxis - the emerging picture Lancet 1988, i: 225-229.

64. Taylor, E.W. Failed antibiotic prophylaxis in elective surgery. Signed editorial. Hosp Update 1991, 17: 455-456.

65. Clyde, W.A. Mycoplasma pneumonia Respiratory Disease Symposium: summation and significance. Yale J Biol Mef 1983, 56: 523-527.

66. Sanford, J.P. Legionnaires' disease: the first thousand days $N$ Engl J Med 1979, 300: 654-656.

67. MacFarlane, J.T., Finch, R.G., Ward, M.J. \& Macrae, A.D Hospital study of adult community-acquired pneumonia Lancet 1982, ii: 255-282.

68. Woodhead, M.A. \& Macfarlane, J.T. Legionnaire's disease: a review of 79 community-acquired cases in Nottingham Thorax 1986, 41: 635-640.

69. Palmer, S.R. Psittacosis in man-recent developments in the UK: A review. J R Soc Med 1982, 75: 262-267.

70. Grayston, J.T., Kuo, C.-C., Campbell, L.A. \& Wang, S.-P Chlamydia pneumoniae sp. nov. for Chlamydia sp. strain TWAR. Int J Syst Bact 1989, 39: 88-90.

71. Marmion, B.P. Rickettsial diseases of man and animals. In Smith, G.R. \& Easmon, C.S.F. (eds) Topley \& Wilson's Bacteriology, Virology and Immunity, 8th ed, vol.3, chapter 35. Edward Arnold, London, 1990, pp. 673-689.

72. Parker, M.T. Enteric infections: typhoid and paratyphoid fever. In: Smith, G.R. \& Easmon, C.S.F. (eds) Topley \& Wilson's Bacteriology, Virology and Immunity, 8th ed, vol. 3 , chapter 22. Edward Arnold, London, 1990, pp. 423-446.

73. Gross, R.J. Escherichia coli diarrhoea. In: Smith, G.R. \& Easmon, C.S.F. (eds) Topley \& Wilson's Bacteriology, Virology and Immunity, 8th ed, vol. 3, chapter 25. Edward Arnold, London, 1990, pp. 469-487.

74. Attridge, S.R. \& Rowley, D. Cholera. In: Smith, G.R. \& Easmon, C.S.F. (eds) Topley \& Wilson's Bacteriology. Virology and Immunity, 8th ed, vol. 3, chapter 24. Edward Arnold, London, 1990, pp. 459-468.

75. Goodwin, C.S., Marshall, B.J., Blincow, E.D. et al. Prevention of nitroimidazole resistance in Campylobacter pylori by coadministration of colloidal bismuth subcitrate: clinical and in vitro studies. J Clin Path 1988, 41: 207-210. 
76. Turnberg, L.A. Traveller's diarrhoea. In: Turnberg, L.A (ed) Clinical Gastroenterology, chapter 10. Blackwell Scientific Publications, Oxford, 1989, pp. 201-210.

77. Collee, J.G. Virulence factors of anaerobes: An overview. In: Borriello, S.P. (ed) Clinical and Molecular Aspects of Anaerobes. Wrightson Biomedical Publishing Ltd, London, 1990, pp. 127-136.

78. De Louvois, J., Gortvai, P. \& Hurley, R. Bacteriology of abscesses of the central nervous system. A multi-centre prospective study. $\mathrm{Br}$ Med J 1977, 2: 981-984.

79. De Louvois, J., Gortvai, P. \& Hurley, R. Antibiotic treatment of abscesses of the central nervous system. $\mathrm{Br} \mathrm{Med}$ $J$ 1977, 2: 985-987.

80. Ingham, H.R., Selkon, J.B. \& Roxby, C.M. Bacteriological study of otogenic cerebral abscesses: chemotherapeutic role of metronidazole. Br Med J 1977, 2: 991-993.

81. Ingham, H.R., High, A.S., Kalbag, R.M. et al. Abscesses of the frontal lobe of the brain secondary to covert dental sepsis. Lancet 1978, ii: 497-499.

82. Anonymous. Chemotherapy of brain abscess. Lancet 1978, ii: $1081-1082$.

83. Alderston, D., Strong, A.J., Ingham, H.R. et al. Fifteen-year review of the mortality of brain abscess. Neurosurgery 1981 , 8: $1-6$.

84. Ispahani, $P$. The therapeutic use of antimicrobial agents: meningitis and brain abscess. In: Greenwood, D. (ed.) Antimicrobial Chemotherapy 2nd ed. Oxford Medical Publications, Oxford, 1989, pp. 289-301.

85. Welsby, P.D. \& Golledge, C.L. Meningococcal meningitis. Br Med J 1990, 300: 1150-1151.

86. Wall, R.A. The chemoprophylaxis of meningococcal infection. J Antimicrob Chemother 1988, 21: 698-699.

87. Finch, R. Bacterial meningitis. Prescribers'J 1989, 29: 2-11.

88. Pearce, J.M. Pelvic inflammatory disease. $\mathrm{Br}$ Med J 1990, 300: 1090-1091.

89. Mitchell, R.G. Miscellaneous bacteria: Capnocytophaga In: Parker, M.T. \& Duerden, B.I. (eds) Topley \& Wilson's Bacteriology, Virology and Immunity, 8th ed, vol. 2, chapter 29. Edward Arnold, London, 1990, pp. 585-587.

90. Rogers, T.R.F. Infections associated with immunodeficiency. In: Smith, G.R. \& Easmon, C.S.F. (eds) Topley \& Wilson's Bacteriology, Virology and Immunity, 8th ed, vol. 3, chapter 10, Edward Arnold, London, 1990, pp. 174-196.

91. British National Formulary. Immunological products and vaccines: pneumococcal vaccine. Chapter 14.4. No. 20. British Medical Association and Royal Pharmaceutical Society of Great Britain, London, 1990, p. 410.

92. Pizzo, P.A. After empiric therapy: what to do until the granulocyte comes back. Rev Infect Dis 1987, 9: 214-219.

93. Klastersky, J., Glauser, M.P., Schimpff, S.C. et al. Prospective randomised comparison of three antibiotic regimens for empirical therapy of suspected bacteremic infection in febrile granulocytopenic patients. Antimicrob Agents Chemother 1986, 29: 263-270.

94. The EORTC International Antimicrobial Therapy Cooperative Group. Ceftazidime combined with a short or long course of amikacin for empirical therapy of Gram-negative bacteremia in cancer patients with granulocytopenia. $N$ Engl J Med 1987, 317: 1692-1698.

95. Chan, C.K., Oppenheim, B.A., Anderson, H. et al. Randomised trial comparing ciprofloxacin plus netilmicin versus piperacillin plus netilmicin for empiric treatment of fever in neutropenic patients. Antimicrob Agents Chemother 1989, 33: $87-91$.

96. Hughes, W.T., Armstrong, D., Bodey, G.P. et al. Guidelines for the use of antimicrobial agents in neutropenic patients with unexplained fever. $J$ Infect Dis 1990, 161: 381-396.

97. Ledingham, I.McA., Alcock, S.R., Eastaway, A.T. et al. Triple regimen of selective decontamination of the digestive tract, systemic cefotaxime and microbiological surveillance for prevention of acquired infection in intensive care. Lancet 1988 , i: $785-790$.

98. Stoutenbeek, C.P., Van Saene, H.K.F., Miranda, D.R. et al. The prevention of superinfection in multiple trauma patients. J Antimicrob Chemother 1984, 14 (Suppl. B): 203-211.
99. Anonymous. Microbial selective decontamination in intensive care patients. Lancet 1988, i: 803-804.

100. Van der Waaij, D. Selective decontamination for prevention of infection in ICU patients. $J$ Hosp Infect 1988, 11 (Suppl. A): $303-308$

101. Van der Waaij, D. The digestive tract in immunocompromised patients: importance of maintaining its resistance to colonization, especially in hospital in-patients and those taking antibiotics. In: Sabbath, L.D. (ed.) Action of Antibiotics in Patients. Huber, Bern, 1982, pp. 104-118.

102. Borriello, S.P. Anaerobic bacteria in diarrhoea and colitis. In: Duerden, B. \& Drasar, B.S. (eds) Anaerobes in Human Disease. Edward Arnold, London, 1991, chapter 21, pp. 351-353.

103. Speller, D.C.E. Hospital-associated infections. In: Smith, G.R. \& Easmon, C.S.F. (eds) Topley \& Wilson's Principles of Bacteriology, Virology and Immunity, 8th ed, vol. 3, chapter 9. Edward Arnold, London, 1990, pp. 155-157.

104. Balakrishnan, G., Simpkins, C., Greig, M. \& Hallworth, D. Catheter-related sepsis. Br J Intensive Care 1991, 1: 17-23.

105. Brown, M.R.W., Costerton, J.W. \& Gilbert, P. Extrapolating to bacterial life outside the test tube. Leading article. J Antimicrob Chemother 1991, 27: 565-567.

106. Wilcox, M.H., Finch, R.G., Smith, D.G.E. et al. Effects of carbon dioxide and sub-lethal levels of antibiotics on adherence of coagulase-negative staphylococci to polystyrene and silicone rubber. J Antimicrob Chemother 1991, 27: 577-587.

107. Wosornu, D., MacIntyre, D. \& Watt, B. An outbreak of isoniazid-resistant tuberculosis in Glasgow, 1981-1988. Resp Med 1990, 84: 361-364.

108. Chemotherapy of tuberculosis: Recommendations of Joint Tuberculosis Committee of the British Thoracic Society. Thorax 1990, 45: 403-408.

\section{Bacterial drug resistance}

109. Levy, S.B. Microbial resistance to antibiotics. In: Good Antimicrobial Prescribing. Lancet, London, 1982, pp. 4-19.

110. Amyes, S.G.B. The success of plasmid-encoded resistance genes in clinical bacteria. $J$ Med Microbiol 1989, 28: 73-83.

111. Hedges, R.W. \& Jacob, A.E. Transposition of ampicillin resistance from RP4 to other replicons. Molec Gen Genet 1974, 132: 31-40.

112. Collee, J.G. The surveillance and control of bacterial and viral infections. MIRCEN J 1986, 2: 61-73.

113. Vaneechoutte, M., Verschraegen, G., Claeys, G. et al. Respiratory tract carrier rates of Moraxella (Branhamella) catarrhalis in adults and children and interpretation of the isolation of $M$. catarrhalis from sputum. J Clin Microbiol 1990, 28: 2674-2680.

114. Powell, M., Koutsia-Carouzou, C., Voutsinas, D. et al. Resistance of clinical isolates of Haemophilus influenzae in United Kingdom 1986. Br Med J 1987, 295: 1765-179.

115. Howard, A.J. \& Williams, H.M. The prevalence of antibiotic resistance in Haemophilus influenzae in Ireland. $J$ Antimicrob Chemother 1989, 24: 963-971.

116. Collee, J.G. Current trends in antimicrobial therapy: the Lister Lecture. Proc $R$ Coll Phys Edinburgh 1988, 18: 16-30.

117. Bergogne-Berezin, E., Joly-Guillou, M.L. \& Vieu, J.F. Epidemiology of nosocomial infections due to Acinetobacter calcoaceticus. J Hosp Infect 1987, 10: 105-113.

118. Casewell, M.W. Epidemiology and control of the 'modern' methicillin-resistant Staphylococcus aureus. J Hosp Infect 1986, (Suppl. A): 1-11.

119. Orange, G. Methicillin-resistant Staphylococcus aureus in intensive care units. Intensive Ther Clin Monitoring 1990, 11: 20-23.

120. Working Party Report. Revised guidelines for the control of epidemic methicillin-resistant Staphylococcus aureus. J Hosp Infect 1990, 16: 351-377.

121. Piercy, E.A., Barbour, D., Luby, J.P. \& Mackowiak, P.A Ciprofloxacin for methicillin-resistant Staphylococcus aureus infection. Antimicrob Agents Chemother 1989, 33: 128-130. 